\title{
Pyrone-based Cu(II) complexes, their characterization, DFT based conformational drift from square planar to square pyramidal geometry and biological activities
}

\author{
PRADEEP KUMAR VISHWAKARMA, JAN MOHAMMAD MIR and \\ RAM CHARITRA MAURYA* \\ Coordination, Bioinorganic and Computational Chemistry Laboratory, Department of P. G. Studies and \\ Research in Chemistry and Pharmacy, R. D. University, Jabalpur 482 001, India \\ e-mail: rcmaurya1@gmail.com
}

MS received 11 August 2015; revised 21 December 2015; accepted 22 January 2016

\begin{abstract}
This work deals with the synthesis and characterization of a series of three $N$-Dehydroacetic acid4-phenyl-3-thiosemicarbazide ( $\mathrm{H}_{2}$ dha-ptsc) Schiff base $\mathrm{Cu}$ (II) complexes based on combined experimental and theoretical approach, having the general composition formula as [Cu(dha-ptsc)(L-L)], where L- $\mathrm{L}$ is $\mathrm{H}_{2} \mathrm{O}$, 2,2-bipyridine (bipy) or 1,10-phenanthroline (phen). $\mathrm{H}_{2} \mathrm{O}$ containing complex acts as origin for the latter two complexes and in due course, the geometry of the complex changes from square planar to square pyramidal. DFT calculations were carried out for both the geometrical forms. B3LYP/LANL2DZ level of theory was used to carry out the required computations. From the overall DFT computations, square pyramidal geometry was found to be more stable as compared to the square planar conformation for the complexes under investigation. Super oxide dismutation, thermal behaviour and electrochemical activity were also studied. The results have shown satisfactory super oxide scavenging potential, high degree of thermal resistance and efficient redox properties for the title complexes. Moreover, charge analysis and nonlinear optical properties were computed to establish a comprehensive note of atomic constituents differing in nature of charge delocalization.
\end{abstract}

Keywords. Copper(II); B3LYP/LANL2DZ; SOD; DFT.

\section{Introduction}

In recent times, major areas of focus involve the bioinorganic chemistry of copper including coordination and spectroscopic properties of prominent classes of copper proteins. In addition, copper-related diseases such as Menkes and Wilsons disease which result due to imbalances in local or global concentration of the metal ion, copper chemistry associated with aging and oxidative stress, including Lou Gehrig's, Alzheimer's and prion diseases have unfurled fascinating copperrelevant investigations. ${ }^{1}$

Ligand selection is always an important asset during the design and synthesis of metal complexes. Biological relevance of Schiff bases stems from the fact that carbon-nitrogen link resembles the peptide bond of proteins. Cogent fabrication and preparation of Schiff base metal complexes are pursued with tremendous fascination. $^{2,3}$ Such type of metal complexes are quite interesting due to their use in numerous fields of applications viz., catalysis, ${ }^{4}$ pharmaceuticals, ${ }^{5}$ and molecular-based materials ${ }^{6,7}$ with second-order nonlinear

\footnotetext{
*For correspondence
}

optical (NLO) properties. ${ }^{8}$ The stratagem in disentangling hydroxypyrones is deduced from the possibility that they can complement biological substrates providing suitable fluorescent stains appropriate for immuno assay procedures and cytological investigation. ${ }^{9}$ A number of hydroxypyrones have attracted researchers to develop potential HIV protease inhibitors owing to the interaction of the pyrone ring with the enzyme active sites. ${ }^{10}$ The metal complexes of hydroxypyrones have reasonable hydrolytic stability and significant lipophilicity. ${ }^{11}$ Hence, significant activities in synthesis, structural investigations, biological activities and density-functional studies of dehydroacetic acid complexes have emerged. ${ }^{12-15}$ The use of thiosemicarbazones (TSCs) on the other hand is among potential chemotherapeutics. These types of compounds are noted for their pharmacological properties, particularly as antiparasitic, ${ }^{16}$ antibacterial and antitumoral agents. ${ }^{17,18}$ 1,10-Phenanthroline/2,2-bipyridine are bidentate chelating ligands that play an important role in the development of coordination chemistry. ${ }^{19}$ Another interesting expedition with these metal complexes is the determination of superoxide dismutation (SOD) potential. Hence, the study of SOD-mimic properties of copper 
complexes may expose many hidden similarities with the superoxide dismutase.

Besides experimental characterization, density functional theory (DFT) computations are the innovative means providing deeper insights about the diversified chemical properties arising in metal-ligand systems. ${ }^{20}$ The four main approaches for calculating molecular properties are semi-empirical, $a b$ initio, DFT and molecular mechanics (MM) methods. These quantum chemical methods can provide information regarding vibrational modes, molecular geometry, ionization potential, heat of formation, force constants, electron density, dipole moments, population analysis, conformational analysis, chemical reaction pathways, thermodynamic properties, etc. However, semi-empirical methods are not so accurate to serve the purpose of approximate calculation of different chemical properties. $^{21-23}$

In view of the diversified importance of copper compounds, it was felt worthy to carry out synthesis and characterization of some ONS donor Schiff base complexes of copper(II) involving dehydroacetic acid and 4-phenyl-3-thiosemicarbazide, and substituted 2,2-bipyridine or 1,10-phenanthroline nitrogen donor chelating ligands. In addition to formulation of the synthesized complexes, a DFT based theoretical approach was used to gain insights on the change of geometry from square planar to square pyramidal with the substitution of 2,2-bipyridine ligand. Moreover, their electrochemical, SOD and thermal applications have also been done.

\section{Experimental}

\subsection{Materials and instruments}

Copper(II) chloride dihydrate and dehydroacetic acid were purchased from E. Merck Limited, Mumbai. 4phenyl-3-thiosemicarbazide was procured from Alfa Aesar, A Johnson Matthey Company England. 2,2bipyridine and 1,10-phenanthroline were purchased from Thomas Baker Chemicals Pvt. Ltd. Mumbai and ethanol from Bengal Chemicals \& Pharmaceuticals, Kolkata. Methanol, acetonitrile, DMSO and DMF were supplied by Sisco Research Laboratories (SRL) Pvt. Ltd., Kolkata. All the chemicals used were of analytical reagent (A. R.) grade and were used as purchased without any further purification.

Elemental analysis was performed on an Elemental Vario ELIII Carlo Erna 1108 analyzer at SAIF, CDRI, Lucknow. Copper composition (\%) of the complexes was determined by the method developed and reported elsewhere. ${ }^{24}$ Solid-state infrared spectra were obtained using $\mathrm{KBr}$ pellets with a Bruker- $\alpha$ T FT-IR Spectrophotometer. The magnetic measurements were carried out on Sherwood Scientific magnetic susceptibility balance (UK) using $\mathrm{Hg}\left[\mathrm{Co}(\mathrm{NCS})_{4}\right]$ as the calibrant. A BASI Epsilon Electrochemical Analyzer was employed to evaluate redox properties using DMSO solution of the complexes containing tetrabutylammonium perchlorate (TBAP) as the supporting electrolyte. An electrically operating melting point apparatus (Kumar Industries, Mumbai) having heating capacity up to $360^{\circ} \mathrm{C}$ was used to determine the decomposition temperatures of the complexes. The Spectrophotometer (Cary-5000 Agilent Technology Germany) was used to record electronic spectra. ESR spectra were recorded at LNT temperature on a X-band ESR spectrometer (JEOL, JES-FA200) using frozen solution at $77 \mathrm{~K}$ at the microwave frequency of $9.11 \mathrm{GHz}$. Thermogravimetric analysis was done by heating the sample at the rate of $10^{\circ} \mathrm{C} / \mathrm{min}$ from $25^{\circ} \mathrm{C}$ up to $1000^{\circ} \mathrm{C}$ on a thermal analyzer at SAIF, I.I.T. Mumbai.

\subsection{Synthesis of Schiff base, $\mathrm{H}_{2}$ dha-ptsc}

The Schiff base ligand was prepared by following the method reported elsewhere. ${ }^{23}$

2.2a Synthesis of $\left[\mathrm{Cu}(\right.$ dha-ptsc $\left.)\left(\mathrm{H}_{2} \mathrm{O}\right)\right]$ 1: To an aqueous-methanolic (v/v 1:10) solution of $\mathrm{CuCl}_{2} \cdot \mathrm{H}_{2} \mathrm{O}$ $(1 \mathrm{mmol}, 0.170 \mathrm{~g})$ was added 1:1 methanol-acetonitrile solution $(10 \mathrm{~mL})$ of $\mathrm{H}_{2}$ dha-ptsc ( $1 \mathrm{mmol}, 0.317 \mathrm{~g}$ ). The resulting mixture was stirred for $30 \mathrm{~min}$ that yielded a greenish precipitate. It was collected by vacuum filtration and washed with methanol-acetonitrile (1:1 v/v) solution. Finally, the desired product was dried and stored in a $\mathrm{CaCl}_{2}$ desiccator. Analysis: $[\mathrm{Cu}$ (dhaptsc) $\left.\left(\mathrm{H}_{2} \mathrm{O}\right)\right]$ 1, $\mathrm{C}_{15} \mathrm{H}_{15} \mathrm{CuN}_{3} \mathrm{O}_{4} \mathrm{~S}$; Formula weight: 396, Decomposition temperature: $230^{\circ} \mathrm{C}$, Yield: $78 \%$, Color: Light green, Elelemtal analysis: Calc./(Found) (\%): C: $45.45 /(45.39), \mathrm{H}: 3.79 /(3.81), \mathrm{N}: 10.60 /(10.59), \mathrm{Cu}$ 15.90/(15.71). IR data $\left(\mathrm{cm}^{-1}\right): v(\mathrm{C}=\mathrm{O})$ lactone: 1686 , $v(\mathrm{C}-\mathrm{O}): 1318, v(\mathrm{C}=\mathrm{N})$ azomethine: $1588, v(\mathrm{C}=\mathrm{S})$ : 680, $v(\mathrm{Cu}-\mathrm{O})$ 530; Electronic spectral data $\lambda_{\max } / \mathrm{nm}$ (extinction coefficient/ $\mathrm{M}^{-1} \mathrm{~cm}^{-1}$ ): 250 (40000), 290 (34482), 382 (26178); Mass spectral data: m/z 396, 398, 317

\subsection{Synthesis of $[\mathrm{Cu}($ dha-ptsc $)($ bipy $)] 2$ and $[\mathrm{Cu}($ dha- ptsc)(phen)] 3}

To an aqueous methanolic solution of $\mathrm{CuCl}_{2} \cdot 2 \mathrm{H}_{2} \mathrm{O}$ $(1 \mathrm{mmol}, 0.170 \mathrm{~g})$ was added $10 \mathrm{~mL} \mathrm{1:1}$ methanolacetonitrile solution of $\mathrm{H}_{2}$ dha-ptsc $(1 \mathrm{mmol}, 0.317 \mathrm{~g}$ ). 
The resulting mixture was stirred for $30 \mathrm{~min}$, and $10 \mathrm{~mL}$ of $1 \mathrm{mmol}$ methanolic solution of desired ligand, 2,2bipyridine or 1,10-phenanthroline was added. By continuous stirring for $30 \mathrm{~min}$ at room temperature, the desired compound was obtained and collected by vacuum filtration using methanol-acetonitrile $(1: 1 \mathrm{v} / \mathrm{v})$ as the washing solution. The products were dried and stored in a $\mathrm{CaCl}_{2}$ desiccator. Analysis: $[\mathrm{Cu}(\mathrm{dha}-$ ptsc)(bipy)] 2, $\mathrm{C}_{25} \mathrm{H}_{21} \mathrm{CuN}_{5} \mathrm{O}_{3} \mathrm{~S}$ : Formula weight: 535; Decomposition temperature: $262^{\circ} \mathrm{C}$; Yield: $71 \%$; Color: Olive green; Elelemtal analysis: Calc../(Found) (\%): C: 56.07/(56.12), H: 3.94/(3.96), N: 13.08/(13.15), Cu 11.77/(11.88); IR data $\left(\mathrm{cm}^{-1}\right): v(\mathrm{C}=\mathrm{O})$ lactone: 1683 , $v(\mathrm{C}-\mathrm{O}): 1276, v(\mathrm{C}=\mathrm{N})$ azomethine: $1572, v(\mathrm{C}=\mathrm{S})$ : $690, v(\mathrm{Cu}-\mathrm{O}) 534$; Electronic spectral data $\lambda_{\max } / \mathrm{nm}$ (Wave number/cm ${ }^{-1}$ ): 266 (37594), 305 (32787), 367 (27248); Mass spectral data: $\mathrm{m} / \mathrm{z}$ 156, 317, 535, 537.

Analysis: $\left[\mathrm{Cu}\left(\right.\right.$ dha-ptsc)(phen)] 3, $\mathrm{C}_{27} \mathrm{H}_{21} \mathrm{CuN}_{5} \mathrm{O}_{3} \mathrm{~S}$ : Formula weight: 559 Decomposition temperature: $258^{\circ} \mathrm{C}$; Yield: 74\%; Color: Olive drub, Elelemtal analysis: Calc./(Found) (\%): C: 57.96/(58.10), H: 3.79/(3.59), N: 12.52/(12.63), Cu 11.27/(11.37) IR data $\left(\mathrm{cm}^{-1}\right): v(\mathrm{C}=\mathrm{O})$ lactone: 1671, $v(\mathrm{C}-\mathrm{O}): 1306, v(\mathrm{C}=\mathrm{N})$ azomethine: $1553, v(\mathrm{C}=\mathrm{S}): 691, v(\mathrm{Cu}-\mathrm{O}) 528$; Electronic spectral data $\lambda_{\max } / \mathrm{nm}$ (Wave number/ $/ \mathrm{cm}^{-1}$ ): 260 (38442), 307 (32573), 372 (26881); EPR data: $\mathrm{A}_{\perp}$ : $45, \mathrm{~A}_{\|}: 155, \mathrm{~A}_{\mathrm{av}}: 81.66, \mathrm{~g}_{\perp}: 2.051, \mathrm{~g}_{\|}: 2.214 \mathrm{~g}_{\mathrm{av}}: 2.105$, $f\left(\mathrm{~g}_{\|} / \mathrm{A}_{\|}\right): 143$.

\subsection{Antibacterial assay}

The antibacterial activity of Schiff base ligand and complex 2 were performed against E.coli and S. pyogenes at a concentration of $200 \mu \mathrm{M}$ in DMSO by the agar diffusion method. ${ }^{25}$ A hot nutrient agar solution $(20 \mathrm{~mL})$ was poured into the sterilized petri dishes and allowed to attain room temperature. The seed layer medium was melted and cooled to ca. $45^{\circ} \mathrm{C}$ with gentle shaking. The previously grown subculture was added to the seed layer medium aseptically and mixed well. It was immediately raked into the petri dish and allowed to attain room temperature. Then wells were made with a sterile cork borer and to these wells, $0.01 \mathrm{~mL}$ of drug solution was added and the plates were allowed to cool for $1 \mathrm{~h}$ to facilitate the diffusion. The plates were incubated at $37^{\circ} \mathrm{C}$ for $48 \mathrm{~h}$. At the end of the incubation period the inhibition zone around the wells was measured. Streptomycin was used as the standard antibacterial agent.

\subsection{Superoxide dismutase (SOD) mimetic activity}

In vitro Superoxide dismutase activity was measured using alkaline DMSO as a source of superoxide radical ion $\dot{\mathrm{O}}_{2}^{-}$and nitrobluetetrazolium (NBT) as $\dot{\mathrm{O}}_{2}^{-}$ scavenger. ${ }^{26}$ In general, $400 \mu \mathrm{L}$ of the sample to be assayed was added to a solution containing $2.1 \mathrm{~mL}$ of $0.2 \mathrm{M}$ potassium phosphate buffer $(2.72 \mathrm{~g}$ in $100 \mathrm{~mL}$ distilled water) $(\mathrm{pH} 7.8)$ and $1 \mathrm{~mL}$ of $56 \mu \mathrm{M}$ NBT in a test-tube. The tubes were kept in ice for $20 \mathrm{~min}$ and then $1.5 \mathrm{~mL}$ of alkaline DMSO solution $(20 \mathrm{mg}$ $\mathrm{NaOH}$ in $1 \mathrm{~mL}$ Water and $99 \mathrm{~mL}$ DMSO) was added while stirring. The absorbance was then monitored at $560 \mathrm{~nm}$ against a sample prepared under similar condition except that $\mathrm{NaOH}$ was absent in DMSO. The measure of SOD activity, expressed as $\mathrm{IC}_{50}$ is the concentration of the substrate or complex, which causes $50 \%$ inhibition of the reduction of NBT.

\subsection{DFT calculations}

The molecular structure of the representative complexes in the ground state were optimized by the DFT method using B3LYP functional combined with LANL2DZ basis sets respectively. ${ }^{27,28}$ Calculations were carried out using Gaussian 09. ${ }^{29}$ The main reason for choosing the LANL2DZ basis set is its inclusion of relativistic effect that is essential for heavy elements. With the aim to arrive at deeper insights of copper ion interaction with the $\mathrm{O}, \mathrm{N}, \mathrm{S}$ coordination environment, the total energy calculations within the DFT frame work were carried out. The optimized structures, vibrational frequencies, HOMO-LUMO energies, Mulliken charges, NBO charges, MESP and NLO properties are the main theoretical evaluations that have been given full consideration in this paper.

\section{Results and Discussion}

Formation of the metal complexes can be represented by the following general equations and scheme 1 .

$$
\begin{gathered}
\text { Stirred for } 30 \text { min at } 30^{\circ} \mathrm{C} \\
\mathrm{CuCl}_{2} \cdot 2 \mathrm{H}_{2} \mathrm{O}+\mathrm{H}_{2} \text { dha-ptsc }\left[\mathrm{Cu}(\text { dha-ptsc })\left(\mathrm{H}_{2} \mathrm{O}\right)\right]+\mathrm{H}_{2} \mathrm{O} \\
\text { Stirred for } 30 \text { min at } 30^{\circ} \mathrm{C} \\
{\left[\mathrm{Cu}(\text { dha-ptsc })\left(\mathrm{H}_{2} \mathrm{O}\right)\right]+\mathrm{L}-\mathrm{L} \longrightarrow[\mathrm{Cu}(\text { dha-ptsc })(\mathrm{L}-\mathrm{L})]+\mathrm{H}_{2} \mathrm{O}}
\end{gathered}
$$




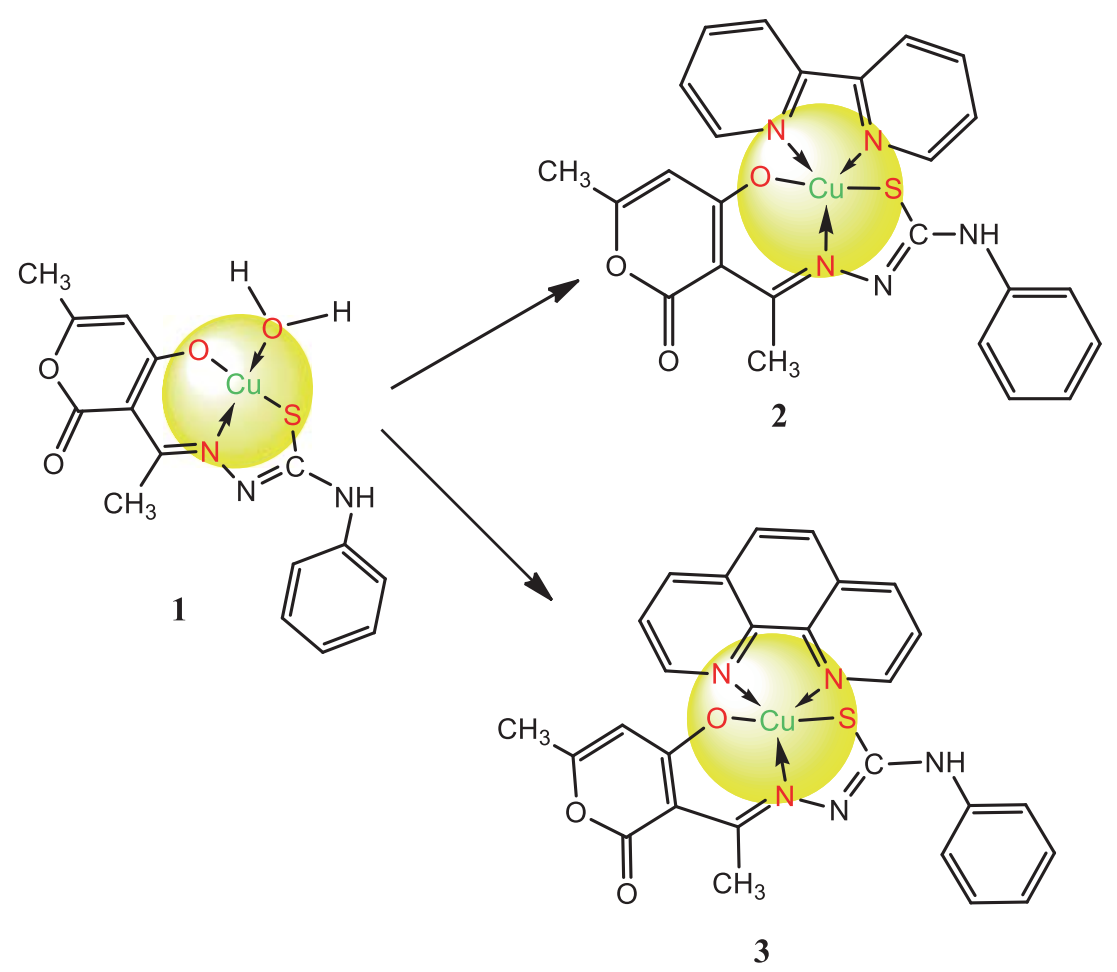

Scheme 1. Synthesis of complexes.

Where, $\mathrm{H}_{2}$ dha-ptsc $\mathrm{H}_{2}$ = 4-hydroxy-6-methyl-2-oxo2H-pyran-3-yl)ethylidene)-N-phenyl-hydrazinecarbothioamide, L-L" (where L-L = 2, 2-bipyridine (bipy) or 1,10-phenanthroline (phen)).

The complexes obtained in this investigation were found soluble in ethanol, methanol, carbon tetrachloride, acetonitrile, DMSO and DMF. Formulation of the complexes has been done on the basis of elemental analyses, IR, EPR and electronic spectral studies, electrochemical studies, TGA, mass spectral, molar conductance and magnetic susceptibility measurements.

\subsection{Spectroscopic studies}

3.1a Infrared spectral studies: Infra-red and ${ }^{1} \mathrm{HNMR}$ spectra (figures S1 and S2 in Supplementary Information) are indicative of the formation of Schiff base. The IR spectrum of the Schiff base ligand exhibits a weak band centered at $3403 \mathrm{~cm}^{-1}$ for $v(\mathrm{OH})$, a strong band at $1701 \mathrm{~cm}^{-1}$ for $v(\mathrm{C}=\mathrm{O})$ (lactone) and another strong band due to $v(\mathrm{C}=\mathrm{N})$ (azomethine) at $1591 \mathrm{~cm}^{-1}$. The presence of $v(\mathrm{NH})$ (hydrazide) and $v(\mathrm{NH})$ (thioamide) at 3209 and $3342 \mathrm{~cm}^{-1}$, respectively, was observed. The presence of $708 \mathrm{~cm}^{-1}$ in Schiff base ligand is most probably due to $v(\mathrm{C}=\mathrm{S})$ or $v(\mathrm{C}-\mathrm{S})$ of the thiosemicarbazone moiety. ${ }^{30}$ Since, the S-H mode of vibration in such cases is so feeble that it cannot be detected. Hence, it may be postulated here that both thione and thiol may coexist under these circumstances. These observations

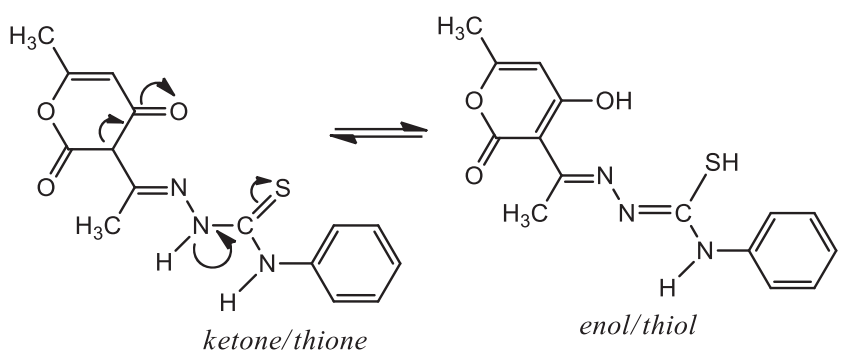

Scheme 2. 2D structure and tautomerization of the synthesized Schiff base.

suggest that the ligands under the present investigation exist in thione/thiol and keto/enol tautomerized forms (scheme 2) in the solid or liquid state.

The Schiff base ligand has six potential donor sites: (i) the enolic oxygen $(\mathrm{OH})$, (ii) azomethine nitrogen, (iii) the hydrazide nitrogen, (iv) thione sulfur, (v) thioamide nitrogen and (vi) lactone oxygen. In the coordination of enolic oxygen after deprotonation, the $v(\mathrm{OH})$ mode at $3403 \mathrm{~cm}^{-1}$ should be absent in the spectra of the complexes. But due to the presence of $v(\mathrm{OH})$ on account of coordinated water (vide infra), it is difficult to say the coordination of enolic oxygen after deprotonation with certainty. However, such coordination is supported by the appearance of $v(\mathrm{C}-\mathrm{O})$ (enolic) at $1306-1319 \mathrm{~cm}^{-1}$ compared to $v(\mathrm{C}-\mathrm{O})$ (enolic) at $1328 \mathrm{~cm}^{-1}$ in the ligands. ${ }^{31}$

The $v(\mathrm{C}=\mathrm{S})$ mode of thione group observed at $708 \mathrm{~cm}^{-1}$ in the Schiff base ligand appears at a new 
position at $680-691 \mathrm{~cm}^{-1}$ due to $v(\mathrm{C}-\mathrm{S})$ (thiolic) in all the complexes suggesting that the bonding of the thiol sulfur atom to copper. ${ }^{32}$ The thiosemicarbazone in the present discussion displays a sharp and strong band due to $v(\mathrm{C}=\mathrm{N})$ of the azomethine group at $1591 \mathrm{~cm}^{-1}$. The observed low energy shift of the band in the complexes at $1554-1572 \mathrm{~cm}^{-1}$ suggests the coordination of the azomethine nitrogen to copper. ${ }^{34}$ The coordination of azomethine nitrogen, enolic oxygen and thiol sulfur as concluded by above discussion, is favorable in the light of the formation of one six membered and one five membered least strained chelate rings with the central copper. ${ }^{33}$ In view of this, the coordination of hydrazide nitrogen, thioamide nitrogen and lactone oxygen is ruled out. This is further supported by the absence of appreciable change in the $v(\mathrm{NH})$ (hydrazide nitrogen) and $v(\mathrm{NH})$ (thioamide group) of the ligands after complexation. Moreover, considering the planarity of the ligands, the coordination of lactone oxygen, is also unlikely due to being back side of the suitable donor sites (i), (ii), (iv) with reference to the details of donor sites given above. In fact the lactone oxygen in these ligands is found to be inert towards coordination to copper as revealed by either no change or some minor upward shifting of $v(\mathrm{C}=\mathrm{O})$ (lactone). The overall infrared spectral studies confirm that the thiosemicarbazone used in the present study behaves as monobasic tridentate ONS-donor ligand. The presence of a broad band centred at $\sim 3423 \mathrm{~cm}^{-1}$ attributed to $v(\mathrm{OH})$ mode of water is most probably due to moisture content in the samples. This is further substantiated with absence of water loss (coordinated) observed in the thermograms (vide infra) either as lattice or as coordinated water in the complexes. The non-ligand band occurring at $528-534 \mathrm{~cm}^{-1}$, has been assigned to the $v(\mathrm{Cu}-\mathrm{O})$ mode. ${ }^{34}$ The IR spectra of the complexes are given in figures S3 and S5 (in SI). Theoretical infrared spectrum of complex $\mathbf{2}$ is shown in figure S4. The important assignments $\left(\mathrm{cm}^{-1}\right)$ 3595, 3254, 3224, 3164, 3046, 1672, 1702, 1587, 1537, 1454, 1360, 1304, 1232, 1181, 1060, 977, 892, 796, 719, 644, 592, 522, 411 and 328 agree with experimental vibrational frequencies and hence prove the reliability of the applied level of theory.

3.1b Electronic spectroscopy of the complexes: Electronic spectra of the investigated complexes shown in figure 1 were recorded in DMSO (0.001M) solutions. Square planar complexes commonly exhibit a broad band $(565-475 \mathrm{~nm}) .{ }^{35}$ The electronic spectra of the present complexes show peaks at 260-307 $\mathrm{nm}$ which are due to intra-ligand transition. One more spectral peak of
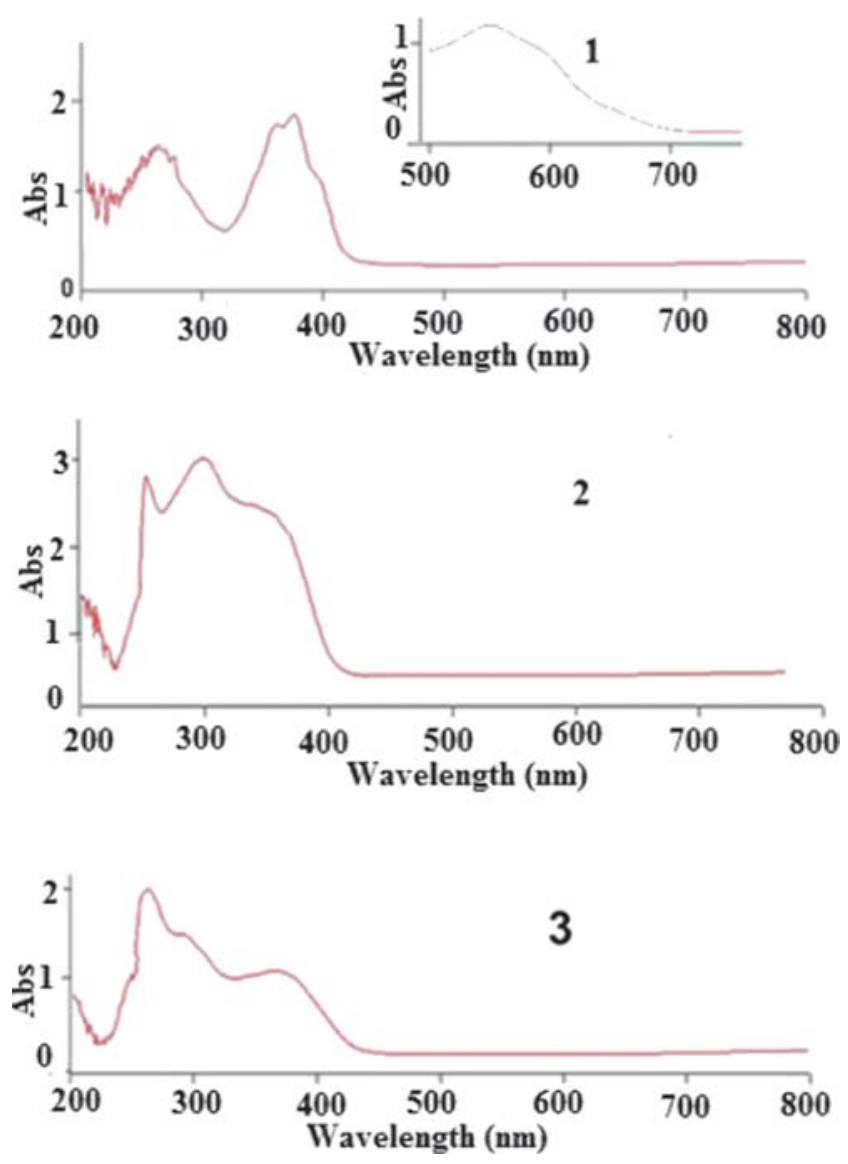

Figure 1. Electronic spectra of complexes 1, 2 and 3 (In 1 a separate magnification of 500-700 $\mathrm{nm}$ range is given).

high intensity at $374-390 \mathrm{~nm}$ is most probably ligand to metal charge transfer (LMCT) transition. ${ }^{36}$ Theoretical electronic spectrum of complex $\mathbf{1}$ is shown in figure S6 (in SI). The results show non-zero oscillatory strength under absorption in the region of 691-1051 nm. This meaningful region coincides with experimental outcome. Hence, from the electronic spectra, square planar and square pyramidal conformations of the complexes are revealed.

\subsection{Magnetic susceptibility and EPR insights}

Magnetic susceptibility (1.72-1.82 B.M.) of all the complexes under question indicate square pyramidal or square planar geometry. ${ }^{37}$ Hence, from the electronic transition (vide supra) and magnetic susceptibility investigations square planar and square pyramidal geometries of the paramagnetic copper complexes are confirmed.

In order to prove the monomeric structure and nature of the bonding within the coordination sphere, the electron paramagnetic spectral study of one of the representative complexes, 3 was performed. The electron 
paramagnetic spectrum of the complex in DMSO at $77 \mathrm{~K}$ is shown in figure S7 (in SI). The complex in the frozen state shows well resolved peaks with low intensities in the low field region and one intense peak in the high field region. The absence of half field signal, observed in the spectrum at $2000 \mathrm{G}$ due to the $\mathrm{m}_{\mathrm{s}}=$ \pm 2 transitions, rules out any $\mathrm{Cu}-\mathrm{Cu}$ interaction. ${ }^{38}$ The value of $\mathrm{g}_{\|}<2.3$ in the present copper complex gives a clear indication of covalent character of the metalligand bond and delocalization of the unpaired electron in the ligand. The trend of $g_{\|}(2.25)>g_{\perp}(2.04)>g$ (2.0036) describes the axial symmetry with the unpaired electron residing in the $\mathrm{d}_{\mathrm{x} 2-\mathrm{y} 2}$ orbital. ${ }^{39}$ For the present complex $\mathbf{3}$, observed $g$ values are $g_{\|}(2.21)>g_{\perp}(2.05)$ $>\mathrm{g}(2.0036)$, which suggest that the unpaired electron lies in the $d_{x 2-y 2}$ orbital. The $A_{\|}(155)>A_{\perp}$ (45) also indicate that the complex has square pyramidal geometry. Hence, the above spectroscopic studies indicate monomeric structure for the complexes $\mathbf{2}$ and $\mathbf{3}$.

\subsection{Electrochemical studies}

Electrochemical CV studies of 0.001 M DMSO solution of complex 3 was investigated in DMSO containing 0.1 $\mathrm{M}$ tetrabutylammonium perchlorate $\left(\mathrm{C}_{4} \mathrm{H}_{9}\right)_{4} \mathrm{NH}_{4} \mathrm{ClO}_{4}$ as the supporting electrolyte, at a glassy carbon working electrode. The CV results of the complex are given in table 1. A representative cyclic voltammogram is shown in figure 2. A negative scan initiated at $1500 \mathrm{mV}$ in the potential range 1500 to $-1500 \mathrm{mV}$ yielded an irreversible couple corresponding to the $\mathrm{Cu}(\mathrm{II}) /(0)$ redox process. ${ }^{40}$ The complex shows an irreversible reduction wave (peak) $\left[\left(\mathrm{Cu}^{+}-\mathrm{Cu}^{0}, \mathrm{E}_{\mathrm{pc}}=-0.463 \mathrm{~V}\right)\right]$ and oxidation wave $\left[\left(\mathrm{Cu}^{+}-\mathrm{Cu}^{2+} \mathrm{E}_{\mathrm{pa} 2}=-0.267 \mathrm{~V}\right)\right]$. In these cases the peak potential difference increases as the scan rate is increased. Constancy of $E_{r}$ shows that in all cases both peaks are complementary to each other. The peak current ratio $I_{p a} / I_{p c}$ is less than unity showing that the electron transfer reaction is followed by a chemical reaction (EC mechanism). ${ }^{40,41}$

\subsection{Thermogravimetric studies}

Thermogravimetric curves of representative compounds, $\mathbf{1}$ and $\mathbf{2}$ are given in in figures S8 and S9 (in SI), respectively. The complexes were subjected to a temperature range of $20-500^{\circ} \mathrm{C}$ for $\mathbf{1}$ and 20 $1000^{\circ} \mathrm{C}$ for 2 at a heating rate of $10^{\circ} \mathrm{C} / \mathrm{min}$. Considering the composition of $\mathbf{1}$, the loss of coordinated water is evident at $120-250^{\circ} \mathrm{C}$. The second step involves the degradation of Schiff base ligand. Compound 2 shows a first weight loss of $2.41 \%$ at $45^{\circ} \mathrm{C}$ (loss of the moisture of the compound) and second weight loss of $32.35 \%$ at $220^{\circ} \mathrm{C}$, calculated as $28.21 \%$ for the decomposition of organic moiety of 2,2bipyridine molecule. The third weight loss of $35.404 \%$ at $600^{\circ} \mathrm{C}$, calculated as $52.057 \%$ for the decomposition of the organic moiety of Schiff base ligand. The final residue (obs. $=28 \%$ ) roughly corresponds to $\mathrm{Cu}_{2} \mathrm{O}$ $($ calcd. $=24.94 \%)$.
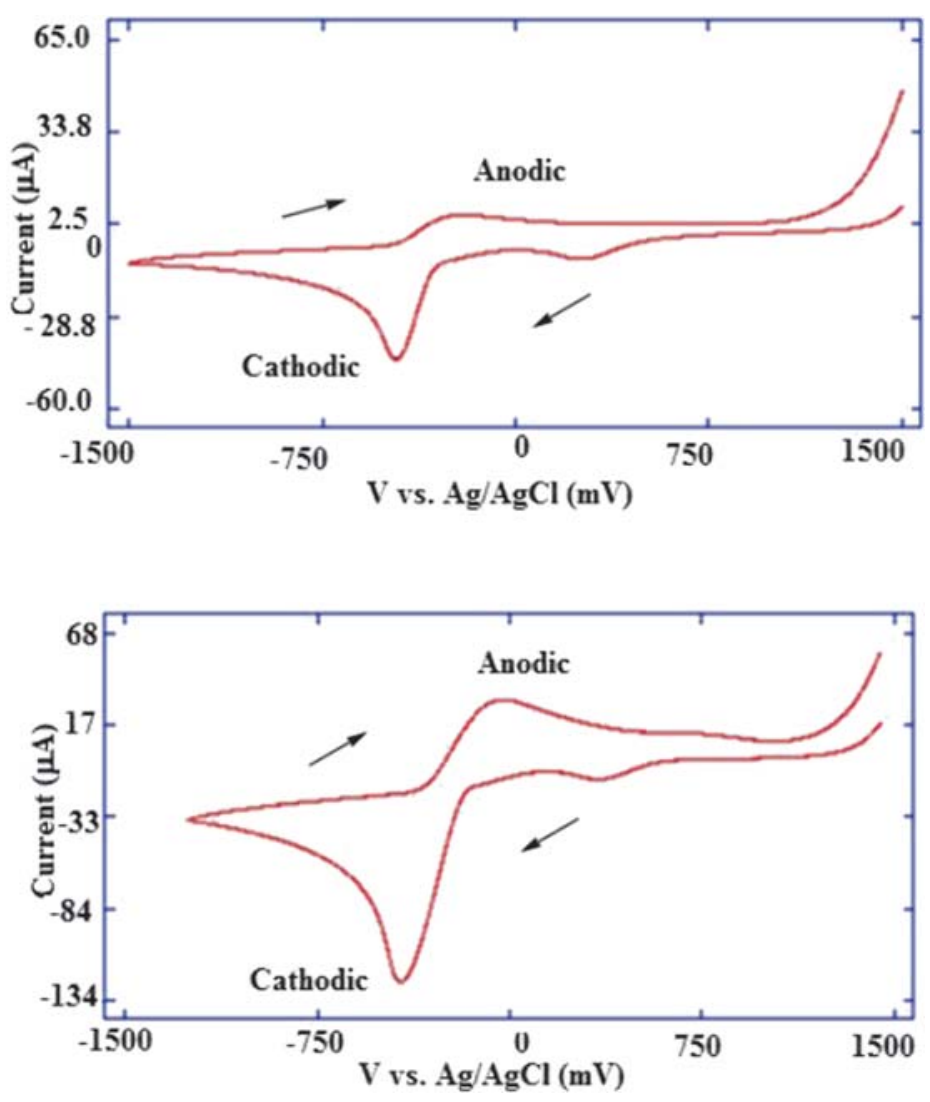

Figure 2. Cyclic voltammograms of [Cu(dha-ptsc)(phen)] 3 in 0.1 M TBAP, at scan rates 200 (top) and 500 (bottom) $\mathrm{mV} / \mathrm{s}$, respectively.

Table 1. Cyclic voltammetric data for the complex [Cu(dha-ptsc)(phen)], 3 .

\begin{tabular}{lccccccccc}
\hline Comp. & Couple & Scan rate $\mathrm{mV} / \mathrm{s}$ & $E_{\mathrm{pc}}(\mathrm{mV})$ & $I_{\mathrm{pc}}(\mu \mathrm{A})$ & $E_{\mathrm{pa}}(\mathrm{mV})$ & $I_{\mathrm{pa}}(\mu \mathrm{A})$ & $\mathrm{E}_{\mathrm{r}}(\mathrm{mV})$ & $\Delta E(\mathrm{mV})$ & $I_{\mathrm{pa}} / I_{\mathrm{pc}}$ \\
\hline $\mathbf{3}$ & $\mathrm{Cu}(\mathrm{II}) /(0)$ & & & & & & & & \\
& & 200 & -524 & 72.64 & -204 & 28.30 & -364 & 320 & 0.39 \\
& 500 & -587 & 103.9 & -140 & 48.54 & -363 & 447 & 0.47 \\
\hline
\end{tabular}

Supporting electrolyte: tetrabutylammonium perchlorate $\left(\mathrm{C}_{4} \mathrm{H}_{9}\right)_{4} \mathrm{NH}_{4} \mathrm{ClO}_{4}(0.1 \mathrm{M})$; concentration of complexes: $0.1 \mathrm{M}$; all the potentials are referenced to $\mathrm{Ag} / \mathrm{AgCl}$ electrode; $\mathrm{E}_{\mathrm{r}}=0.5\left(\mathrm{E}_{\mathrm{pa}}+\mathrm{E}_{\mathrm{pc}}\right)$, where $\mathrm{E}_{\mathrm{pa}}$ and $\mathrm{E}_{\mathrm{pc}}$ are anodic and cathodic potentials. 


\subsection{Mass spectrometric analysis}

ESI Mass spectra of complexes $\mathbf{1}$ and $\mathbf{2}$ were recorded between a mass range of 100-700. Mass spectra of the compounds are shown in figure S10 and S11 (in SI). The different mass ionization peaks of positive mode in both the cases are in full agreement with their composition. ${ }^{63} \mathrm{Cu}$ and ${ }^{65} \mathrm{Cu}$ isotope based molecular ion peaks, $\mathrm{m} / \mathrm{z} 396$ and 398 in $\mathbf{1}$ and m/z 535 and 537 in compound 2 are consistent. $\mathrm{m} / \mathrm{z} 317$ in both the cases indicates Schiff base ligand and m/z 156 ion peak indicates the presence of 2, 2-bipyridine in square pyramidal complex, 2.

\subsection{Antibacterial screening}

The synthesized compounds have been evaluated for their antibacterial action. The antibacterial tests were carried out using the agar diffusion method at $200 \mu \mathrm{M}$. Streptomycin was used as a standard drug. Escherichia coli and $S$. pyogenes were used as the test organisms. Results have been recorded in the form of inhibition zones (diameter, $\mathrm{mm}$ ) and activities are given in table 2. The histogram and images of inhibition zone for antibacterial activity shown in figure 3 and figure $\mathrm{S} 12$, respectively. It is observed that the metal complexes are more potent bactericides than the ligands. The enhancement in the activity of complex can be explained on the basis of chelation theory. ${ }^{42,43}$ Chelation reduces the polarity of the metal ion considerably, mainly because of the partial sharing of its positive charge with donor groups and possible $\pi$ electron delocalization over the whole chelate ring. Chelation can reduce not only the polarity of the metal ion, but it increases the lipophilic character of the chelate, and the interaction between metal ion and the lipid is favored. This may lead to the breakdown of the permeability barrier of the cell, resulting in interference with the normal cell processes. If thegeometry and charge distribution

Table 2. Antibacterial activity of Schiff base and complex (2): inhibition zone in $\mathrm{mm}$.

\begin{tabular}{lcc}
\hline Compounds & E.coli & S. pyogenes \\
\hline $\mathrm{H}_{2}$ dha-ptsc & 27 & 19 \\
{$[$ Cu(dha-ptsc)(bipy)] 2} & 36 & 24 \\
Streptomycin & 42 & 28 \\
\hline
\end{tabular}

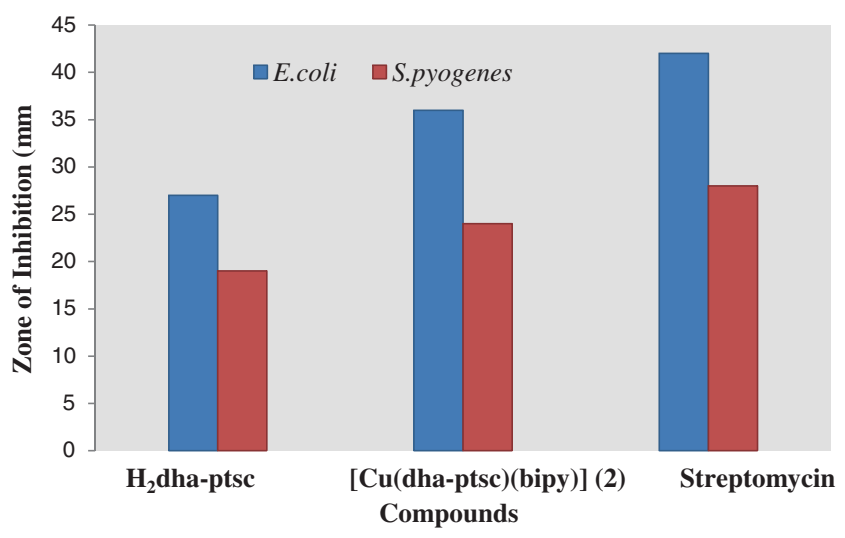

Figure 3. Histograms showing antibacterial activity.

around the molecule are incompatible with the geometry and charge distribution around the pores of the bacterial cell wall, penetration through the wall by the toxic agent cannot take place and this will prevent the toxic reaction within the pores. Chelation is not the only criterion for antibacterial activity. Therefore, antibacterial property of the metal complex cannot be ascribed to chelation alone, but it is an intricate blend of several contributions.

\subsection{Superoxide dismutase activity}

Superoxide dismutase activity (SOD mimetic activities) of the complexes has have been measured by the Nitro blue tetrazoliumchloride (NBT) assay. ${ }^{44-46}$ The SOD activity was measured by monitoring the reduction of NBT by $\dot{\mathrm{O}}_{2}^{-}$generated by the alkaline DMSO. The calculated fraction causing 50\% inhibition of NBT reduction is called $\mathrm{IC}_{50}$. Concentration equivalent to one unit of SOD activity ( $\mathrm{IC}_{50}$ values), together with the IC50 value of native SOD are given in table 3. The graphical representation is shown in figure 4 . The results obtained of $\mathrm{IC}_{50}$ of the two representative complexes $\mathbf{2}$ and $\mathbf{3}$ are 28 and $30 \mu \mathrm{mol} \mathrm{dm}{ }^{-3}$, respectively. The observed IC50 values of the present investigated complexes are comparable with the various reported values for the copper(II) complexes, ${ }^{47-49}$ but are less active than the native SOD. The superior activities of these complexes may be accredited to the flexibility of two different ONS donor chelating Schiff base ligand $\left(\mathrm{H}_{2}\right.$ dha-ptsc $)$ and $\mathrm{N}, \mathrm{N}$ donor neutral ligands (L-L), L-L = (bipy) or (phen) in a ternary system shows bio-catalytic activity towards the dismutation of superoxide anion and follows a two-step process shown below. ${ }^{49}$

$$
\begin{aligned}
& \mathrm{O}_{2}^{--}+\left[\mathrm{Cu}^{\text {II }}(\text { dha-ptsc })(\mathrm{L}-\mathrm{L})\right] \Longrightarrow \mathrm{O}_{2}+\left[\mathrm{Cu}^{\mathrm{I}}(\text { dha-ptsc })(\mathrm{L}-\mathrm{L})\right] \\
& \mathrm{O}_{2}^{\bullet-}+\left[\mathrm{Cu}^{\mathrm{I}}(\text { dha-ptsc })(\mathrm{L}-\mathrm{L})\right]+2 \mathrm{H} \Longrightarrow \mathrm{H}_{2} \mathrm{O}_{2}+\left[\mathrm{Cu}^{\mathrm{II}}(\text { dha-ptsc })(\mathrm{L}-\mathrm{L})\right]
\end{aligned}
$$


Table 3. Superoxide dismutase activity of copper (II) complexes.

\begin{tabular}{|c|c|c|c|}
\hline Sl. No. & Complexes* & $\mathrm{IC}_{50}\left(\mu \mathrm{mol} \mathrm{dm}{ }^{-3}\right)$ & Ref. \\
\hline 01 & Native SOD & 0.04 & 43 \\
\hline 02 & {$[\mathrm{Cu}(\mathrm{SAA})(\mathrm{MeImH})]$} & 35 & 44 \\
\hline 03 & {$\left[\mathrm{Cu}(\mathrm{L}) \mathrm{Cl}_{2}\right]$} & 22 & 36 \\
\hline 04 & {$\left[\mathrm{Cu}(\mathrm{L}) \mathrm{Br}_{2}\right]$} & 18 & 36 \\
\hline 05 & {$[\mathrm{Cu}($ dha-ptsc)(bipy) $] 2$ this work } & 28 & this work \\
\hline 06 & {$[\mathrm{Cu}($ dha-ptsc)(phen) $] 3$ this work } & 31 & this work \\
\hline
\end{tabular}

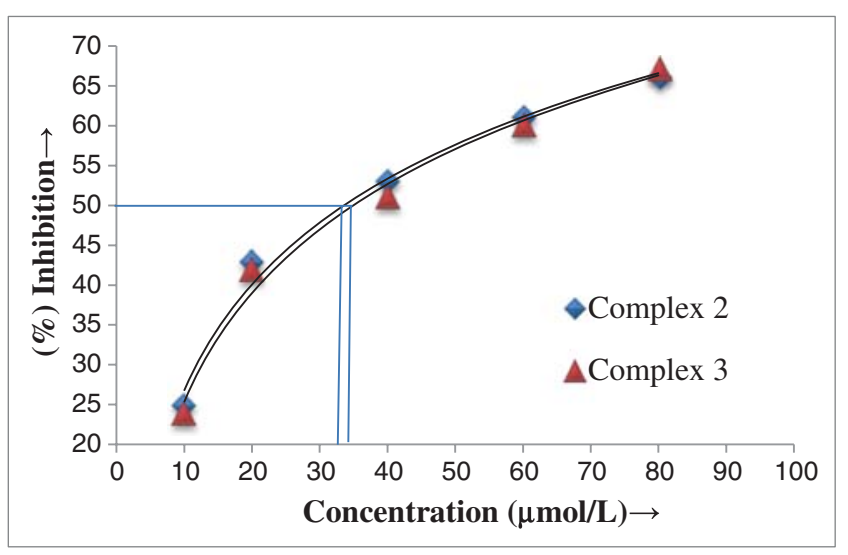

Figure 4. Superoxide dismutase activity of complexes 2 and 3 .

The SOD mimic activity (enhanced/suppressed) can be attributed to the factors like nature of ligands as well as the overall geometrical distortions in the molecular structure. $^{44,50}$

\subsection{Molecular geometrical parameters and the geometry drift}

The optimized geometries computed for square planar complex 1 and square pyramidal complex $\mathbf{2}$, calculated by B3LYP/LANL2DZ levels are shown in figure 5. The assignments are in accordance with atom numbering scheme. In complex 1, two diagonal angles of the coordination sphere are $174-175^{\circ}$ and the four angular projections by the four bonds are $80-90^{\circ}$. Hence, a wellestablished square planar geometry. As the optimization has been made in the gaseous state, the little distortion the square planarity clarifies the stability of the complex. In case of complex $\mathbf{2}$, the presence of ternary copper(II) structures consisting of a tridentate ONS donor Schiff base, a bidentate ligand (NN-donor) and a copper(II) center in the discrete monomeric species. The coordination geometry is ascertained by the observed $\tau$ value (the structure index is defined as $\tau=(\beta-\alpha) / 60$, where $\alpha$ and $\beta$ are the largest coordination angles), such a square planar geometry was observed in a copper(II) complexes where the values of $\tau$ lie in the range $0.05-0.17 .^{51,52}$ Complex 2 has a distorted square pyramidal $(4+1)$ geometry, the distortion $(\tau=0.24)$ from square pyramidal geometry was again ascertained by $\tau$ value; for a perfect square pyramidal geometry the $\tau$ value should be $0 .{ }^{53,54}$ The largest distortions from the square pyramidal geometry are indicated by the angles $\mathrm{O}(7)-\mathrm{Cu}(23)-\mathrm{S}(13)=142.59^{\circ}$ and $\mathrm{Cu}(23)-\mathrm{N}(26)-\mathrm{C}(25)=127.638^{\circ}$. Similar copper(II) complexes, having distorted square pyramidal geometry geometries, have also been reported by Patel et al. ${ }^{55}$ From the tables S1 and S2) in SI), the geometrical drift from complex $\mathbf{1}$ to complex $\mathbf{2}$ is remarkably favoured by the reaction of substitution of coordinated water by bipy ligand. The overall study of energy content, charge delocalization, dipole moment variation and bond sensitivity show that the increase in donation site over copper centre by one unit from the square planar conformation is seemingly well pronounced in stabilizing power.

\subsection{Natural bond orbital (NBO) analysis}

The natural bond orbital (NBO) analysis of a representative complex 2 was carried out by B3LYP/LANL2DZ level basis set. The NBO analysis could be used to estimate the delocalization of electron density between occupied Lewis-type orbitals and formally unoccupied non-Lewis NBOs (antibonding or Rydberg), which corresponds to a stabilizing donor-acceptor interaction. ${ }^{56}$ The natural atomic charges of the selected atoms are listed in table S3. The highest and lowest negative charge to be found on the $\mathrm{O}(7)(-0.70117 \mathrm{e})$ and $\mathrm{S}(13)$ $(-0.27512 \mathrm{e})$, respectively. Thus the observed bond length of $\mathrm{Cu}-\mathrm{O}(7), 2.0096 \AA$ and $\mathrm{Cu}-\mathrm{S}(13) 2.3840 \AA$ are different. According to the NBO, the natural electron configuration of $\mathrm{Cu}$ is: [core] $4 \mathrm{~s}(0.32) 3 \mathrm{~d}(9.42)$ $4 \mathrm{p}(0.51)$. Thus, (17.9951) core electrons, (10.24726) valence electrons (on $4 \mathrm{~s}, 3 \mathrm{~d}$ and $4 \mathrm{p}$ atomic orbitals) and (0.01061) Rydberg electrons (mainly on $4 \mathrm{p}, 4 \mathrm{~d}$ 


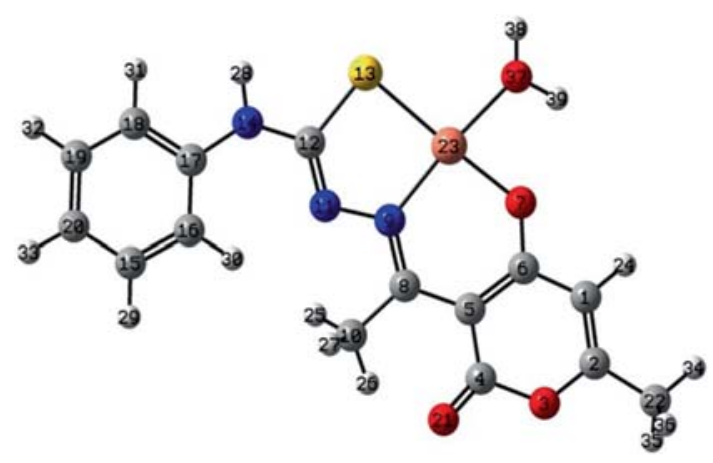

1

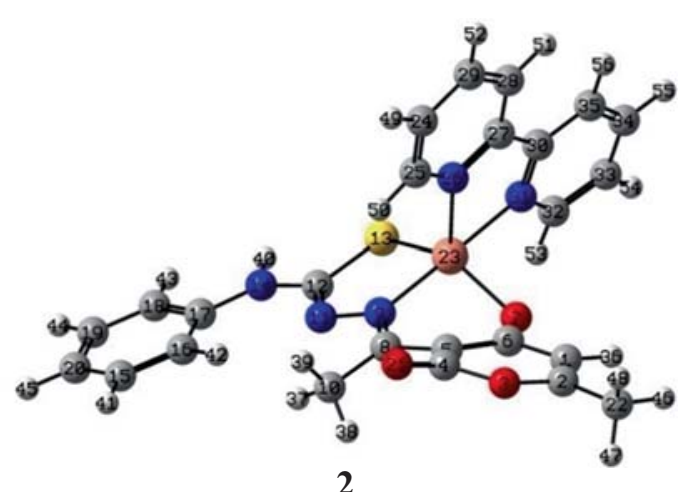

2

Figure 5. Optimized molecular structures of complexes $\mathbf{1}$ and 2.

and $5 \mathrm{p}$ orbitals) give 28.25338 electrons. This is consistent with the calculated natural charge on $\mathrm{Cu}$ atom +0.74662 in the copper complex, which corresponds to the difference between $27.98602 \mathrm{e}$ and the total number of electrons in the isolated $\mathrm{Cu}$ atom $29 \mathrm{e}$. In addition, the atoms $\mathrm{O}(7), \mathrm{N}(9), \mathrm{S}(13), \mathrm{N}(26)$ and $\mathrm{N}(31)$ have negative charge $-0.70117,-0.38785,-0.27512,-0.51421$ and $-0.51571 \mathrm{e}$, respectively. Thus, the positive atomic charge upon the copper(II) was substantially reduced as a consequence of electron density donation from oxygen sulfur, azomethine nitrogen and cyclic nitrogen donor atoms.

The natural atomic charge is based on the theory of the natural population analysis (NPA). The analysis is carried out with natural bond orbitals (NBO). They are linear combinations of the natural atomic orbitals. The derivation of a valence-shell atomic orbital (NAO) involves diagonalization of the localized block of the full density matrix of a given molecule associated with basic functions on that atom. A distinguishing feature of NAO's is that they meet the simultaneous requirement of orthonormality and maximum occupancy. In a polyatomic molecule the NAO's mostly retain onecenter character, and thus they are optimal for describing the molecular electron density around each atomic center. Natural bond orbitals are linear combinations of the NAO's of two bonded atoms.

\subsection{Frontier molecular orbital Analysis}

The frontier molecular orbitals play a vital role in the electrical and optical properties, as well as in UVVis spectra and chemical reactions. ${ }^{57}$ One can determine the way the molecule interacts with other species. Hence, they are called the Frontier orbitals. The HOMO is the orbital that primarily acts as an electron donor and the LUMO is the orbital that largely acts as the electron acceptor, and the gap between HOMO and LUMO characterizes the molecular chemical stability. ${ }^{58}$
Selected six important FMOs viz., HOMO-2, HOMO1, HOMO, LUMO, LUMO+1 and LUMO+ 2 are carried out for the complex 2 . The observed energies and the energy separation between HOMO-LUMO, HOMO-1LUMO+1 and HOMO-2-LUMO+2 are presented in table S2 (in SI). As seen in figure 6, $\mathrm{LUMO}+2$ is mainly localized on the ring pyridine, while $\mathrm{LUMO}+1$ and LUMO are mainly localized on the $\mathrm{C}-\mathrm{N}$ and $\mathrm{C}=\mathrm{N}$ groups of pyridine, respectively. HOMO is mainly localized on the $\mathrm{C}=\mathrm{S}$ group, while HOMO-2 and HOMO-1 are mainly localized on the benzene ring of thiosemicarbazide. The electron arrangements of MO are in the presence of single electron in the HOMO for complex justifies that it is paramagnetic due to one unpaired electron. Thus, the HOMO in the present complex may be termed as singly occupied molecular orbital (SOMO).

The energy of the frontier molecular orbitals in terms of ionization energy (IE) and electron affinity (EA) of the representative complex 2 are related using Koopmans's theorem. ${ }^{59}$ The absolute electronegativity $\left(\chi_{\text {abs }}\right)$ and absolute hardness $(\eta)$ are related to IE and EA. ${ }^{60}$ Hard molecules have a large gap and soft molecules have a small gap between HOMO-LUMO. ${ }^{61}$ Another important property related to the dipole moment and hardness is electrophilicity index $(\omega)$, global softness $(\mathrm{S}),{ }^{62}$ absolute electronegativity $\left(\chi_{\mathrm{abs}}\right)$, absolute hardness $(\eta)$ of complex are represented in table S2.

\subsection{Molecular electrostatic potential (MESP)}

The MESP surface diagram is used to understand the reactive behavior of a molecule, in that negative regions can be regarded as nucleophilic centers, whereas the positive regions are potential electrophilic sites. MESP is related to the Electron Density (ED) and it is a very useful descriptor in understanding sites for electrophilic and nucleophilic reactions as well as hydrogen 


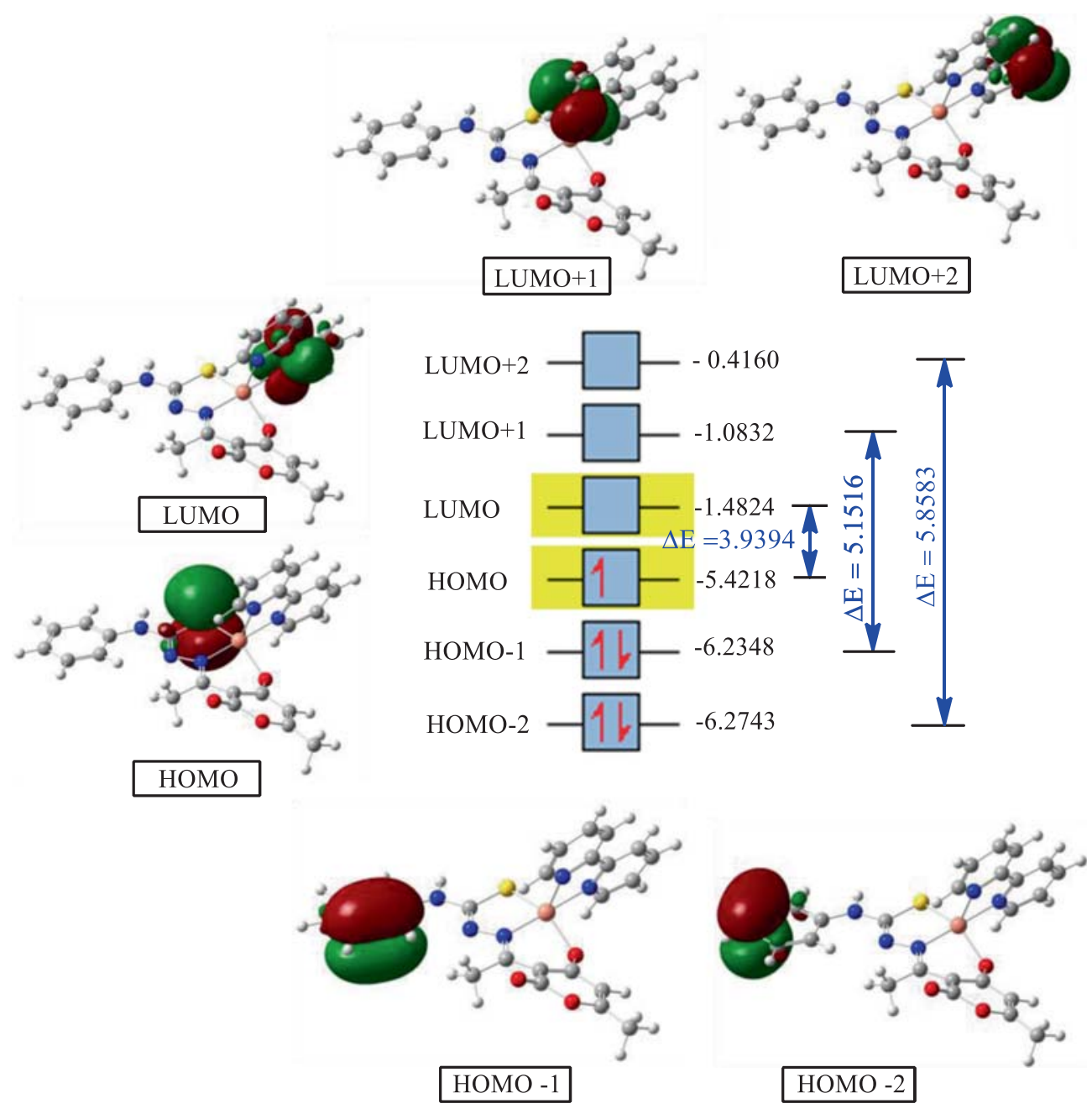

Figure 6. HOMO-LUMO Structure with the energy level diagram of 2.

bonding interactions. ${ }^{63}$ The MESP displays molecular shape, size and electrostatic potential values of the complex 2 in figure 7, which shows that the carbonyl oxygen is the most negative potential region, while hydroxyl/methoxy oxygen is the region of moderate negative potential. The hydrogen and carbon atoms of the compound bear positive potentials. The predominance of green region in the MESP surface corresponds to a potential halfway between the two extremes red and dark blue color.

\subsection{Nonlinear optical properties}

Nonlinear optical properties of the representative $\mathrm{Cu}$ (II) complex 2 calculated in terms of $\mathrm{x}, \mathrm{y}, \mathrm{z}$ components have been listed in table S4 (in SI). Such an exploration plays a vital role in understanding the structureproperty relationship which helps in designing novel NLO materials. It is well known that higher values of dipole moment $(\mu)$, the polarizability $(\alpha)$, anisotropy of
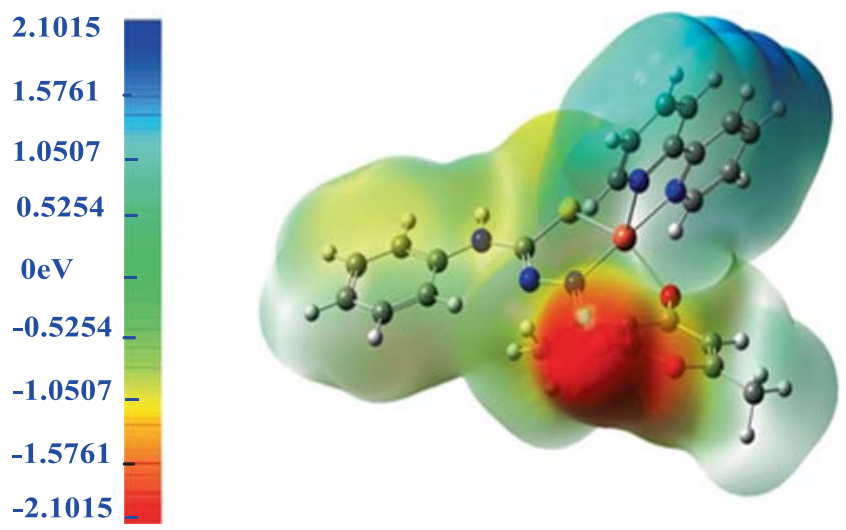

Figure 7. Molecular electrostatic potential surface of complex 2 in eV mapped on the electronic density isosurface of 0.02 a.u.

the polarizability $(\Delta \alpha)$, the first static calculated hyperpolarizability $\left(\beta_{0}\right)$ and Second Hyperpolarizabilities $(\gamma)$ are essential for more active NLO properties. The first hyperpolarizability $\left(\beta_{0}\right)$ of this novel molecular system is calculated using DFT method, based on the finite field 
approach. In the presence of an applied electric field, the energy of a system is a function of the electric field. First hyperpolarizability is a third rank tensor that can be described by a $3 \times 3 \times 3$ matrix. The 27 components of the 3D matrix can be reduced to ten components: $\beta_{\mathrm{xxx}}$, $\beta_{\mathrm{yyy}}, \beta_{\mathrm{zzz}}, \beta_{\mathrm{xyy}}, \beta_{\mathrm{xxy}}, \beta_{\mathrm{xxz}}, \beta_{\mathrm{xzz}}, \beta_{\mathrm{yzz}}, \beta_{\mathrm{yyz}}$ and $\beta_{\mathrm{xyz}}$ due to the Kleinman symmetry. ${ }^{64}$

The calculated dipole moment $(\mu)$, the polarizability $(\alpha)$, anisotropy of the polarizability $(\Delta \alpha)$ and the first static calculated hyperpolarizability $\left(\beta_{0}\right)$ of the title compound 2 and their respective values in the same order are $11.6541 \mathrm{D}, 29.087 \times 10^{-24},-26.218 \times 10^{-24}$, $3.837 \times 10^{-30}$ and $-7.770 \times 10^{-29}$ esu. The calculated hyperpolarizability of the title compound is 29.515 times that of the standard NLO material, urea $(0.13 \times$ $\left.10^{-30} \mathrm{esu}\right){ }^{65} \mathrm{We}$ conclude that the title compound is an attractive object for future studies of nonlinear optical properties. ${ }^{66-68}$

\section{Conclusions}

The study of copper(II) complexes under investigation possess distorted square pyramidal geometry. The combined experimental and theoretical approaches support in declaring that the complexes are quite stable. Their redox potential and superoxide dismutase mimicking behaviour might prove helpful in designing drugs that are more potent since the bactericidal properties of the complexes are well pronounced. Besides, the calculations used in this study persuades us to state that the basis sets and functions are reliable.

\section{Supplementary Information (SI)}

Refer Supplementary Information for figures S1-S12 and tables S1 to S4. Supplementary Information is available at www.ias.ac.in/chemsci

\section{Acknowledgements}

The authors are thankful to Vice Chancellor, Rani Durgavati University, Jabalpur, Madhya Pradesh, India for encouragement. Analytical facilities provided by the Central Drug Research Institute, Lucknow, India, and the Regional Sophisticated Instrumentation Centre, Indian Institute of Technology, Mumbai, India, are gratefully acknowledged. All the theoretical calculations were carried out at the Department of PG Studies and Research in Chemistry and Pharmacy R. D. University Jabalpur.

\section{References}

1. Gaggelli E, Kozlowski H, Valensin D and Valensin G 2006 Chem. Rev. 1061995

2. Rezaeivala M and Keypour H 2014 Coord. Chem. Rev. 280203

3. Frischmann P D, Jiang J, Hui J K H, Grzybowski J J and MacLachlan M J 2008 Org. Lett. 101255

4. Decortes A, Castilla A M and Kleij A W 2010 Angew. Chem. Int. Ed. 499822

5. Maurya R C and Mir J M 2014 Int. J. Sci. Eng. Res. 5 305

6. Che C M, Kwok C C, Lai S W, Rausch A F, Finkenzeller W J, Zhu N and Yersin H 2010 Chem. Eur. J. 16233

7. Righetto S and Di Bella S 2014 Dalton Trans. 432168

8. Nayar C R and Ravikumar R 2014 J. Coord. Chem. 671

9. Cindric M, Vrdoljak V, Kajfez T, Novak P, Saranovic A B, Strukan N and Kamenar B 2002 Inorg. Chim. Acta 32823

10. Rangel M, Tamura A, Fukushima C and Sakurai H 2001 J. Biol. Inorg. Chem. 6128

11. Comba P 1993 Coord. Chem. Rev. 1231

12. Chitrapriya N, Mahalingam V, Zeller M, Jayabalan R, Swaminathan K and Natarajan K 2008 Polyhedron 27 939

13. Zouchoune F, Zendaoui S, Bouchakri N, Djedouani A and Zouchoune B $2010 \mathrm{~J}$. Mol. Struc. Theochem. 94578

14. Kannan S, Sivagamasundari M, Ramesh R and Liu Y 2008 J. Organo-met. Chem. 6932251

15. Fouad D M, Ismail N M, El-Gahami M A and Ibrahim S A 2007 Spectrochim. Acta A 67564

16. De Oliveira R B, de Souza-Fagundes E M, Soares R P P, Andrade A A, Krettli A U and Zani C L 2008 Eur. J. Med. Chem. 431983

17. Khan S A and Yusuf M 2009 Eur. J. Med. Chem. 442597

18. Kovala-Demertzi D, Demertzis M A, Filou E, Pantazaki A, Yadav P N, Miller J R, Zheng Y and Kyriakidis D A 2003 Biometals 16411

19. Summers L A 1978 Adv. Heterocycl. Chem. 221

20. De Abreu H A, Guimaraes L and Duarte H A $2006 \mathrm{~J}$. Phys. Chem. A 1107713

21. Arora K, Khan A R and Sharma K P 2002 Orient. J. Chem. 18319

22. Maurya R C, Malik B A, Mir J M and Vishwakarma P K 2015 J. Mol. Struct. 1083343

23. Maurya R C, Malik B A, Mir J M, Vishwakarma P K, Rajak D K and Jain N 2015 J. Coord. Chem. 682902

24. Vogel A I 1996 In A Text Book of Qualitative Inorganic Analysis ( $7^{\text {th }}$ edition) (N. J.: Prentice Hall)

25. Collee J G, Duguid J P, Farser A G and Marmion B D 1989 (Eds.) In Practical Medical Microbiology (New York: Churchill Livingstone)

26. Siddiqi Z A, Sharma P K, Shahid M, Khalid M and Kumar S 2011 J. Mol. Struct. 994295

27. Becke A D 1993 J. Chem. Phys. 98648

28. Lee C, Yang W and Parr R C 1998 Phys. Rev. B 37785

29. Frisch M J et al. 2010 GAUSSIAN 09 (Revision C.01) (Gaussian, Inc.: Wallingford CT)

30. Banwell C N and McCash E M 1997 In Fundamentals of Molecular Spectroscopy (4 ${ }^{\text {th }}$ edition) (New Delhi: Tata McGraw Hill) p. 86

31. Maurya R C and Rajput S 2008 Int. J. Synth. Charac. 1 101 
32. Joseph M, Suni V, Kurup M R P, Nethaji M, Kishore A and Bhat S G 2004 Polyhedron 233069

33. Maurya R C and Rajput S 2007 J. Mol. Struct. 833133

34. Maurya R C, Patel P and Rajput S 2003 Synth. React. Inorg. Met. Org. Chem. 33801

35. Lever A B P 1984 In Inorganic Electronic Spectroscopy $2^{\text {nd }}$ Edition (Amsterdam: Elsevier) p.570

36. (a) Maurya R C, Sharma P and Sutradhar D 2003 Synth. React. Inorg. Met. Org. Chem. 33 669; (b) Dasgupta S, Khatua S, Bertolasi V and Bhattacharjee M 2007 Polyhedron 262574

37. Raman N, Raja Y P and Kulandaisamy A 2001 Proc. Indian Acad. Sci. (Chem. Sci.) 113183

38. Raman N, Kulandaisamy A, Thangaraja C, Manisankar P, Viswanathan S and Vedhi C 2004 Transit. Metal. Chem. 29129

39. Gaballa A S, Asker M S, Barakat A S and Teleb S M 2007 Spectrochim. Acta A 67114

40. Patel R N, Gundla V L N and Patel D K 2008 Polyhedron 271054

41. Parveen S and Arjmand F 2005 Indian J. Chem. A 44 1151

42. Thimmaiah K N, Lloyd W D and Chandrappa G T 1985 Inorg. Chim. Acta 10681

43. Franklin T J and Snow G A 1971 In Biochemistry of Antimicrobial Action $2^{\text {nd }}$ edition (London: Chapman and Hall)

44. Patel R N, Shukla K K, Singh A, Choudhary M, Chauhan U K and Dwivedi S 2009 Inorg. Chim. Acta 362489

45. Bhirud R G and Shrivastava T S 1991 Inorg. Chim. Acta 179125

46. Bhirud R G and Shrivastava T S 1990 Inorg. Chim. Acta 179121

47. Patel R N, Singh N, Shukla K K and Gundla V L N 2005 Spectrochim. Acta A 611893

48. Glugliarelli G and Cannistraro S 1984 Nuovo Cimento 4D 194
49. Singh N, Shukla K K, Patel R N, Chauhan U K and Shrivastava R 2003 Spectrochim. Acta A 593111

50. Siddiqi Z A, Shahid M, Khalid M and Kumar S 2009 Eur. J. Med. Chem. 442517

51. Pierrs J L, Chatutemps P, Refait S, Beguin C, Marzouki A E, Serratrice G, Aman E S and Rey P 1995 J. Am. Chem. Soc. 117965

52. Patel R N, Gundla V L N and Patel D K 2008 Polyhedron 271054

53. Addison A W, Rao T N, Rudijk J, Rijn J V and Verschoor G C 1984 J. Chem. Soc. Dalton 1349

54. Gupta S, Mukherjee A, Nethaji M and Chakravarty A R 2005 Polyhedron 241922

55. Patel R N, Singh N and Gundla V L N 2006 Polyhedron 253312

56. Reed E, Curtiuss L A and Weinhold F 1988 Chem. Rev. 88899

57. Fleming J 1976 In Frontier Orbitals and Organic Chemical Reactions (London: Wiley)

58. Fukui K 1982 Science 218747

59. Brabec C J, Sariciftci N S and Hummelen J C $2001 A d v$. Funct. Mater. 112001

60. Ebenso E E, Arslan T, Kandemirli F, Love I, Ogretir C, Saracoglu M and Moron S A 2010 Int. J. Quantum. Chem. 1102614

61. Pearson R G 1993 Acc. Chem. Res. 26250

62. Maurya R C, Malik B A, Mir J M, Vishwakarma P K, Rajak D K and Jain N 2015 J. Mol. Struct. 1099266

63. Scrocco E and Tomasi J 1979 Adv. Quantum. Chem. 11 115

64. Kleinman D A 1962 Phys. Rev. 1261977

65. Adant M, Dupuis L and Bredas L 2004 Int. J. Quantum. Chem. $\mathbf{5 6} 497$

66. Karthick T, Balachandran V, Perumal S and Nataraj A 2011 J. Mol. Struct. 1005202

67. Xavier R J and Dinesh P 2014 Spectrochim. Acta. A 118 999

68. Dammak H, Feki H, Boughzala H and Abid Y 2015 Spectrochim. Acta. A 1371235 